\title{
Gutiérrez Girardot, Rafael. 2014. \\ En torno a "El anticristiano", de Nietzsche. Bogotá: Desde Abajo.
}

Diego Felipe Paredes-Goicochea

Universidad Autónoma de Colombia (Colombia)

Pensamiento y Cultura | ISSN: 0123-0999 | eISSN: 2027-5331 pensam.cult | Vol. 18-1 | Junio de 2015 | pp. 176-181

DOI: 10.5294/pecu.2015.18.1.7 
En este breve texto sobre El anticristo, de Nietzsche, escrito en 1996 y editado recientemente por Damián Pachón Soto en la Colección Nuevas Ideas de la Editorial Desde Abajo, Rafael Gutiérrez Girardot busca evitar que el diálogo crítico y filosófico que caracteriza a este libro póstumo sea oscurecido por su tono polémico y provocador. Esta estrategia de lectura supone que el libro de Nietzsche no es principalmente un tratado retórico y desafiante que exalta la figura del enemigo de Jesús en el Apocalipsis de Juan, sino una compleja crítica al cristianismo considerado como un "poder histórico-universal". Por eso, para Gutiérrez Girardot, "El Anticristo es, así, El Anticristiano" (Gutiérrez 2014, 57).

Esta sugestiva tesis tiene la virtud de mostrar que, con la crítica al cristianismo, Nietzsche no apunta exclusivamente a las instituciones eclesiales y sus prácticas, o incluso a los desarrollos de esta religión en particular, sino que se dirige a los alcances de la experiencia espiritual de su tiempo: "La crítica al cristianismo de Nietzsche es una compleja y laberíntica toma de conciencia de la época, en la que él se encuentra y a la que se opone" (92). De este modo, Gutiérrez Girardot no vacila en asociar la polémica nietzscheana contra el cristianismo a lo que el filósofo alemán llama décadence y nihilismo. El cristianismo comparte con la metafísica la carencia de un sentido histórico y, por tanto, participa en el desprecio hacia todo lo cambiante, hacia todo lo que se encuentra en permanente devenir. Pero también comparte con la moral el rechazo a la voluntad de poder, esto es, a la caracterización de la vida como "instinto de crecimiento, de duración, de acumulación de fuerzas" (El anticristo, $\$ 7,39$ ). Por eso, de la experiencia del cristianismo surge el animal de rebaño, el ser humano dócil y débil que, para Nietzsche, encarna los valores de decadencia, aquellos valores nihilistas que son hostiles a la vida. Esta experiencia caracteriza, entonces, el espíritu de una época. En este sentido amplio, el cristianismo no es más que otra palabra para nombrar una cultura que es antitética del poderío vital.

Así pues, la crítica de Nietzsche al cristianismo no puede ser desligada de su crítica a la filosofía occidental. Gutiérrez Girardot entiende dicha afirmación en dos sentidos. Por un lado, la teología cristiana incorpora en su acervo de valores los conceptos clásicos de la filosofía occidental, como 'sustancia', 'causalidad', 'verdad'. Por otro lado, 
en la filosofía occidental, en particular en la moderna, se mantiene de manera encubierta el principio tomista philosophia ancilla theologiae. Esto último quiere decir que, pese a los desarrollos de la Ilustración, la filosofía continúa siendo, en cuanto metafísica, una solapada ontoteología. Por eso, aunque la crítica nietzscheana al cristianismo se inscribe dentro del horizonte de lo que sociológicamente se conoce como "secularización", es una superación o, mejor, una suerte de profundización de este proceso. Para Gutiérrez Girardot, la "muerte de Dios", que el hombre frenético anuncia en el conocido aforismo 125 de La ciencia jovial, apunta a esta dirección. El pensador colombiano insiste, en varios momentos de su escrito, en que la crítica de Nietzsche es una crítica desde dentro, una mea culpa, puesto que, pese a su pensamiento intempestivo, el filósofo alemán no pudo escapar al hecho de ser hijo de su tiempo, y en este sentido, no cesó de combatir contra su propia biografía.

Según Gutiérrez Girardot, la Ilustración kantiana dio un importante paso hacia el cuestionamiento de la sacralidad de la religión al querer someterla al examen público y libre de la crítica. Este paso después fue acompañado, desde orillas diversas, por la filosofía de los jóvenes hegelianos y la "teología de la mediación" que buscaba una conciliación entre el cristianismo y el conocimiento científico. En la crítica kantiana y su consecuente desarrollo en la filosofía y teología alemanas del siglo XIX, Gutiérrez Girardot ve el germen de la historización del dogma cristiano: "Al ser sometida a la crítica, la religión fue expuesta a la pregunta: ¿de dónde proviene su 'sacralidad', por qué esta sacralidad pretende eximir a la religión de su crítica?, es decir, ¿cuál es la legitimidad histórica de esa sacralidad?" (Gutiérrez 2014, 73). En estas preguntas emerge ciertamente el interrogante por la génesis de dicha pretensión y la consecuente exigencia de la búsqueda de una respuesta a través de la combinación metodológica entre historia y filología. A mi juicio, aquí se encuentra apenas en ciernes lo que Nietzsche después llamará, bajo su propia perspectiva, "filosofar histórico", y que en la etapa tardía de su obra recibe el nombre de "genealogía".

En los aforismos iniciales del primer volumen de Humano, demasiado humano, Nietzsche desenmascara el defecto común de los filósofos, su pecado original: toman al ser humano, incluso al mundo 
entero, como una aeterna veritas. Pero el filosofar histórico, por su parte, muestra que "todo ha devenido; no hay datos eternos, lo mismo que no hay verdades absolutas" (Humano, demasiado humano, $\$ 2$, 44). Este filosofar intenta, entonces, develar que los grandes valores de la cultura occidental - los de la metafísica, pero también aquellos de la moral y del cristianismo-, considerados por la tradición como atemporales y trascendentes, tienen su origen en situaciones y motivaciones demasiado humanas. Este filosofar, que anticipa la búsqueda genealógica por las condiciones en las que emergen, se desarrollan y se transforman determinadas valoraciones, es resaltado por Gutiérrez Girardot cuando afirma: "Comprender el cristianismo como un 'poder histórico universal' significa una historización del cristianismo, es decir, una 'desdogmatización' de la doctrina, una reducción de lo concebido como atemporal y extrahumano al devenir y al mundo humano" (Gutiérrez 2014, 65). En efecto, en El anticristo, Nietzsche dilucida la psicología del cristianismo a través de la pregunta por su génesis y es esta búsqueda del origen la que revela el tipo de instintos que se han apoderado durante años de esta religión.

Sin embargo, lo que se ha resaltado como un acierto del texto de Gutiérrez Girardot - su intento por leer la crítica de Nietzsche al cristianismo en conexión con el movimiento espiritual de Occidente - trae consigo una desventaja. A mi modo de ver, el rechazo del título "anticristo" y su reemplazo por el de "anticristiano", aunque evita las referencias exclusivas al enemigo de Jesús en el Evangelio de Juan, no acentúa lo suficiente el lugar central que ocupa la figura de "Cristo" en el ataque nietzscheano al cristianismo. En su texto, Nietzsche distingue entre la valoración de Jesús como "hijo de Dios", que inaugura una nueva práctica de la vida, y el Jesús crucificado, comprendido como una víctima inocente que se sacrificó por los pecados de los culpables. El primero encarna el Evangelio, anuncia la Buena Nueva a través de su obrar que muestra que el Reino de los Cielos es una experiencia en acto y no una promesa futura. Su mensaje es su práctica y su muerte no busca "redimir a los hombres", sino confirmar cómo se ha de vivir. El segundo, por su parte, es la antítesis del Evangelio o, si se quiere, el buen mensaje convertido en 
una "mala nueva". Él es la base sobre la cual se erige la Iglesia y, de este modo, el comienzo del espíritu de venganza y del odio instintivo a toda realidad. Por eso, sostiene Nietzsche, "la historia del cristianismo - a partir de la muerte en la cruz - es la historia del mal entendimiento, cada vez más grosero, de un simbolismo originario" (El anticristo, $\$ 37,84$ ).

Nietzsche realiza así una genealogía del cristianismo que desenmascara el paso del Evangelio al "disangelio", inaugurado precisamente con la muerte de Cristo en la cruz. Es cierto, como bien lo señala Gutiérrez Girardot, que esta mala nueva es la interpretación de la "teologización institucional” (Gutiérrez 2014, 85), llevada a su extremo por Pablo. Pero no hay que olvidar que es Cristo el símbolo de este falso comienzo. Fue la fe en el "crucificado" lo que dio paso al resentimiento frente al mundo terrenal, y con su muerte se puso de manifiesto la necesidad del juicio final, como correlato de la doctrina de la resurrección. Así, fue a partir de ese acontecimiento que se instauró la creencia en la inmortalidad del alma, y con ella no solo se desplazó el centro de gravedad de la vida hacia el más allá, sino que se legitimó la igualdad como identidad de rango que, para Nietzsche, es un atentado contra el pathos de la distancia entre los seres humanos. Por eso, el "anticristo" es el símbolo que se contrapone al "automalentendido psicológico" (El anticristo, $\$ 39,88$ ) iniciado con la interpretación vengativa del asesinato del redentor. De ahí que el "anticristiano" no pueda ser desligado de la figura del "anticristo".

A pesar de su tesis principal, Gutiérrez Girardot no parece desconocer este último hecho en sus repetidas referencias a la "filosofía del futuro" que anuncia Nietzsche. En esta filosofía, Dionisio ocupa el lugar central, así sea como señal de "un retorno a un pasado remoto" (Gutiérrez 2014, 81). Apoyándose en la "grecomanía" nietzscheana - que por lo demás me parece difícil de sostener después de El nacimiento de la tragedia-, el pensador colombiano llama la atención sobre la oposición entre este dios pagano y Cristo. Sin embargo, resulta desconcertante que Gutiérrez Girardot entienda este retorno de Dionisio como una especie de mesianismo que viene a llenar el vacío de la muerte de Dios con la "transmutación de todos los valores". Como lo decía, en su crítica a Cristo, Nietzsche rechaza precisamente la estructura de la promesa que 
se asocia a la espera del Mesías. Es en este sentido que El anticristo, como libro póstumo, confirmaría la importancia de lo dicho por Nietzsche al final de su Ecce homo: “Se me ha comprendido? - Dionisio contra el Crucificado...” (Ecce homo, 145).

\section{Referencias bibliográficas}

Gutiérrez Girardot, Rafael. 2014. En torno a "El anticristiano", de Nietzsche. Bogotá: Desde Abajo.

Nietzsche, Friedrich. 1996. Humano, demasiado humano. Madrid: Akal.

Nietzsche, Friedrich. 2005. Ecce homo. Madrid: Alianza Editorial.

Nietzsche, Friedrich. 2014. El anticristo. Madrid: Alianza Editorial. 